\title{
Association between blood pressure dipping patterns and hypertension-mediated organ damage among Nigerians with newly- diagnosed hypertension
}

\author{
*Dele-Ojo, B.F. ${ }^{1}$, Ogunmodede J.A. ${ }^{2}$, Ojo O.D. ${ }^{3}$, Kolo P.M. ${ }^{2}$, Katibi I.A. ${ }^{2}$, Omotoso A.B. ${ }^{2}$, \\ Adeoye M.A. ${ }^{4}$, Adesokan $A^{5}$.
}

\begin{abstract}
Introduction: Abnormal blood pressure (BP) dipping patterns are associated with increased cardiovascular risk among Africans. This study determined the association between BP dipping patterns and hypertension-mediated organ damage among patients with newly-diagnosed hypertension.
\end{abstract}

Methods: Ambulatory BP monitoring and echocardiography were carried out on 120 participants. Participants were categorized based on the ratio of night-time to day-time systolic BP into 4 patterns: Normal dipper $(\geq 10 \%$ but $<20 \%$ ), non-dippers ( $\geq 0 \%$ but $<10 \%)$, reverse dippers $(<0 \%)$ and extreme dippers $(\geq 20 \%)$.

Result: Fifty-one (42.5\%) were males, the mean age and body mass index were $44.2 \pm 9.8$ years and $27.1 \pm 4.4 \mathrm{~kg} / \mathrm{m} 2$ respectively. The non-dipping pattern was the most prevalent while the reverse dipping had the lowest mitral E/A ratio. Office systolic blood pressure was the only predictor of left ventricular hypertrophy $(\mathrm{OR}=1.050,95 \% \mathrm{CI}=1.004-1.098$; $\mathrm{p}$-value $=0.034)$.

Conclusions: The non-dipping pattern was the most prevalent abnormal dipping pattern while the reverse dippers had the highest risk of hypertension-mediated organ damage. Office blood pressure was the only predictor of left ventricular hypertrophy. Hence, office BP measurement as well as ambulatory blood pressure measurements are potentially important tools in risk stratification in resource-poor settings of sub-Saharan Africa.

Keywords: Dipping patterns, hypertension-mediated organ damage, echocardiography, left ventricular hypertrophy, Nigeria.

\footnotetext{
*Corresponding author

Dele-Ojo, B.F.

ORCID-NO: http://orcid.org/0000-0001-9505-6581.

Email: bolade.dele-ojo@eksu.edu.ng

${ }^{1}$ Department of Medicine, Ekiti State University Teaching Hospital, Ado-Ekiti, Nigeria.

${ }^{2}$ Department of Medicine, University of Ilorin, PMB 1515, Ilorin, Nigeria.

${ }^{3}$ Department of Surgery, Afe Babalola University, Ado-Ekiti, Nigeria.

${ }^{4}$ Department of Medicine, University College Hospital, Ibadan, Nigeria.

${ }^{5}$ Director, R \&D Pharmaceutical Company, PreciseMed Glasgow, United Kingdom
} 


\title{
Association entre les schémas de baisse de la pression artérielle et les lésions organiques induites par l'hypertension chez les Nigérians souffrant d'hypertension nouvellement diagnostiquée
}

\author{
*Dele-Ojo, B.F. ${ }^{1}$, Ogunmodede J.A. ${ }^{2}$, Ojo O.D. ${ }^{3}$, Kolo P.M. ${ }^{2}$, Katibi I.A. ${ }^{2}$, Omotoso A.B. ${ }^{2}$, \\ Adeoye M.A. ${ }^{4}$, Adesokan $A^{5}$.
}

\section{Resume}

Introduction: Les baisses de tension artérielle (TA) anormales sont associées à un risque cardiovasculaire accru chez les Africains. Cette étude a déterminé l'association entre les schémas de baisse de la PA et les lésions organiques induites par l'hypertension chez les patients souffrant d'hypertension nouvellement diagnostiquée.

Méthodes: Une surveillance ambulatoire de la PA et une échocardiographie ont été réalisées sur 120 participants. Les participants ont été classés en fonction du rapport de la PA systolique nocturne à la PA systolique diurne en 4 modèles : balancier normal $(=10 \%$ mais $<20 \%$ ), non-dippers $(=0 \%$ mais $<10 \%$ ), balanciers inversés $(<0 \%)$ et les plongeurs extrêmes $(=20 \%)$.

Réultat: Cinquante et un (42,5\% ) éaient des hommes, 1' âge moyen et l'indice de masse corporelle étaient respectivement de 44,2 $\pm 9,8$ ans et de $27,1 \pm 4,4 \mathrm{~kg} / \mathrm{m} 2$. Le modèle sans pendage était le plus répandu tandis que le pendage inversé avait le rapport E/A mitral le plus faible. La pression artérielle systolique en cabinet était le seul prédicteur de l'hypertrophie ventriculaire gauche (OR =1,050, IC à $95 \%$ $=1,004-1,098$; valeur $\mathrm{p}=0,034$ ).

Conclusions: Le modèle sans pendage était le modèle anormal de trempage le plus répandu, tandis que les plongeurs inversés présentaient le risque le plus élevé de dommages aux organes liés à l'hypertension. La pression artérielle en cabinet était le seul facteur prédictif d'hypertrophie ventriculaire gauche. Par conséquent, la mesure de la PA en cabinet ainsi que les mesures ambulatoires de la pression artérielle sont des outils potentiellement importants dans la stratification du risque dans les milieux à faibles ressources del'Afrique subsaharienne.

Mots-clés: schémas de trempage, lésions organiques induites par l'hypertension, échocardiographie, hypertrophie ventriculaire gauche, Nigéria.

\author{
*Corresponding author \\ Dele-Ojo, B.F. \\ ORCID-NO: http://orcid.org/0000-0001-9505-6581 \\ Email: bolade.dele-ojo@eksu.edu.ng \\ ${ }^{1}$ Department of Medicine, Ekiti State University Teaching Hospital, Ado-Ekiti, Nigeria.
${ }^{2}$ Department of Medicine, University of Ilorin, PMB 1515, Ilorin, Nigeria.
${ }^{3}$ Department of Surgery, Afe Babalola University, Ado-Ekiti, Nigeria.
${ }^{4}$ Department of Medicine, University College Hospital, Ibadan, Nigeria.
${ }^{5}$ Director, R \&D Pharmaceutical Company, PreciseMed Glasgow, United Kingdom
}

Research Journal of Health Sciences subscribed to terms and conditions of Open Access publication. Articles are distributed under the terms of Creative Commons Licence (CC BY-NC-ND 4.0). (http://creativecommons.org/licences/by-nc-nd/4.0).

http://dx.doi.org/10.4314/rejhs.v9i3.1 


\section{INTRODUCTION}

Systemic hypertension (SH) is a global public health problem and a leading cause of death worldwide (1). Hypertension is more common among African population groups and they have a higher incidence of hypertensionrelated cardiovascular disease when compared with people of other races (2-4). However, the optimal management of $\mathrm{SH}$ begins with appropriate diagnosis and proper classification of blood pressure (BP) phenotypes. Identifying the BP dipping patterns will help in further risk stratification of patients with newly-diagnosed hypertension. Twenty-four (24)-hour ambulatory blood pressure monitoring (ABPM) has been encouraged by the European Society of Cardiology guideline in patients with newlydiagnosed SH (5). The evaluation of BP circadian profiles and the diagnosis of nocturnal hypertension are some of the benefits of ABPM (5). Ambulatory night-time BP value is a better predictor of cardiovascular disease (CVD) risk when compared with the daytime BP value (6). The night-time ABPM value provides additional predictive information over daytime ABPM value (7). The night-time systolic BP is the most potent predictor of cardiovascular event and mortality $(7,8)$. Higher night-time systolic BP was found to be associated with all-cause mortality, while both higher night-time systolic BP and diastolic BP were associated with increased risk of cardiovascular disease (coronary heart disease and stroke) $(9,10)$. A previous study revealed that night-time dosing with antihypertensive medications reduced major cardiovascular events such as CVD death, stroke and myocardial infarction by $67 \%$, probably because of night-time BP attenuation effect (6).

Some local studies done, were mostly on the prevalence of circadian rhythm in patients with hypertension (11-13), but there is a dearth of studies on the association between blood pressure dipping patterns and hypertension-mediated organ damage among patients with hypertension. Hence, this study determined the association between BP dipping patterns and hypertensionmediated organ damage among Nigerian patients with newly-diagnosed hypertension.

\section{MATERIALS AND METHODS}

A cross-sectional study that consisted of 120 patients with newly-diagnosed $\mathrm{SH}$, who were 18 years and above. All participants gave written informed consent. Participants were seen at the Medical Outpatient Departments of UITH between June 2014 to December 2014. The patients in this study were antihypertensivenaïve adults whose systolic blood pressure (SBP) were equal to or greater than $140 \mathrm{mmHg}$ and /or diastolic blood pressure (DBP) of equal to or greater than $90 \mathrm{mmHg}$ (14). Individuals with other co-morbidities and pregnant females were excluded from the study. ABPM and echocardiography were carried out on all the study participants. They were recruited consecutively. Each patient had the office BP measured by the auscultatory method in both arms using the mercury sphygmomanometer while relaxed and sitting down with both feet resting on the floor. The mean of three BP readings in the arm with the higher $\mathrm{BP}$ reading was taken as the patients' office BP. Both the systolic and diastolic BP were determined to the nearest $2 \mathrm{mmHg}$. This was followed by 24-hour ABPM using CONTEC ambulatory blood pressure monitors according to the recommendations of the European Society of Hypertension practise guidelines (15). The procedure and handling of the ambulatory blood pressure monitor were explained to the subjects after which patients' details were entered and the monitoring was initialized. The machine was programmed to read half-hourly from 7 a.m. to 10 p.m. and hourly from 10 p.m. to 7 a.m, in order to reduce the frequency of interference with sleep during the night-period. An appropriate cuff size was chosen and this was applied immediately to the participant's non-dominant bare arm. Participants were discharged home to continue their normal activities and were asked to return after 24 hours for retrieval of the ABP monitor. They were advised to avoid any activity during the measurements and to abstain from smoking, alcohol use and the consumption of caffeinated drinks throughout the period of study.

Dipping pattern was categorized as follows (15): Normal dipping pattern occurred when the reduction in the mean SBP during the night period was greater than or equal $10 \%$ but lesser than $20 \%$ of mean SBP during the day (that is: $\geq 10 \%$ but $<20 \%$ ); non-dipping pattern occurred when the reduction in the mean SBP during the night was greater than or equal to $0 \%$ but lesser than $10 \%$ of mean SBP during the day (that is $\geq 0 \%$ but $<10 \%$ ); reverse dipping pattern occurred when mean night-time BP was greater than the mean of day-time BP and the nocturnal dip was less than $0 \%$; extreme dipping pattern (extreme dippers) occurred when night-time SBP fall was greater than or equal to $20 \%$ (that is $\geq$ $20 \%$ ) of the mean day-time SBP. 


\section{Echocardiography}

Two-dimensional transthoracic echocardiography was carried out by a Cardiologist with training in echocardiography using Sonos-2,000; Philips Medical Systems, Amsterdam, Netherlands and standardized protocols. (16) Left ventricular dimensions including left ventricular internal diameter in diastole (LVIDd), interventricular septal thickness in diastole (IVSd), and posterior wall thickness in diastole (PWTd), were assessed according to American Society of Echocardiography (ASE) recommendations (16).

Left ventricular mass index (LVMI) was calculated using the ASE - cubed formula (16):

$\operatorname{LVMI}(\mathrm{g} / \mathrm{m})=$

$\underline{\left.1.04\left[(\mathrm{LVIDD}+\mathrm{PWTD}+\mathrm{IVSD})^{3}\right]-(\mathrm{LVIDD})^{3}\right]-0.8+0.6}$ BSA

Where BSA is Body Surface Area.

Left ventricular hypertrophy (LVH) was defined as increased LVMI $\geq 96 \mathrm{~g} / \mathrm{m}^{2}$ in women and $\geq 116$ $\mathrm{g} / \mathrm{m}^{2}$ in men) $(17,18)$.

Additionally, doppler echocardiography was obtained according to the recommendations of quantification of Doppler Echo of the ASE (16). The LV diastolic flow pattern was assessed by Doppler studies via the Apical 4 -chamber and 5-chamber views. The trans-mitral, pulmonary and aortic velocities were determined. The mitral inflow $\mathrm{E}$ and $\mathrm{A}$ velocities were recorded as the mitral E/A ratio. The deceleration time (DT) and isovolumetric relaxation time (IVRT) were also obtained. Pulmonary venous flow (PVF) velocity recording was carried out via the apical 4 chamber view using the pulsed wave Doppler by placing the cursor in the right upper pulmonary vein close to the inter-atrial septum. By this, the peak systolic $S$ and diastolic D flow velocities and the ratio of $\mathrm{S} / \mathrm{D}, \mathrm{AR}$ (atrial reversal) were obtained. Peak early transmitral filling velocity (E), peak late trans-mitral filling velocity (A), the ratio of early and late trans-mitral filling velocity (E/A), deceleration time (DT) of the early transmitral filling velocity, isovolumetric relaxation time (IVRT) is the time interval between aortic valve closure and mitral valve opening.

The LV diastolic function was classified as (16):

Normal: E/Aratio $=1-2, \mathrm{DT}=160-240$ msecs.

Impaired relaxation: Reduced E velocity, increased A velocity; E/A ratio $<1$, prolonged DT $(>200 \mathrm{msec})$, prolonged IVRT $(>100 \mathrm{msec}), \mathrm{S}>\mathrm{D}$

Pseudonormalization: $\mathrm{E} / \mathrm{A}$ ratio $=1-2$;

$\mathrm{DT}=160-240 \mathrm{msecs}, \mathrm{S}<\mathrm{D}$.
Restrictive Pattern: E/A ratio $>2$ (that is increased $\mathrm{E}$ velocity, decreased A velocity), shortened DT $(<160 \mathrm{~ms})$ shortened IVRT $(<60 \mathrm{msec})$.

Ethical approval was obtained from the ethics and research committee of UITH with approval protocol number ERC/2015/06/07.

\section{Statistical Analysis}

The data were analysed using the Statistical Package for Social Sciences (SPSS) version 23. Categorical variables were expressed as proportions and percentages while continuous variables were expressed as means with standard deviations (SD). Participants' characteristics were calculated for the overall sample and later stratified into three dipping patterns (normal dipping, non-dipping, and reverse dipping). Using analysis of variance (ANOVA), the mean of the 3 categories of blood pressure dipping patterns groups was compared and post-hoc analysis was done with the Tukey test for multiple pair-wise comparisons to determine where the significance lies. Binary logistic regression was used to determine the predictors of LVH. For all tests, a p-value $<0.05$ was taken as being statistically significant.

\section{RESULTS}

The general characteristics of the study population, including office BP, ambulatory blood pressure and the echocardiographic indices are shown in Table 1. A total of 120 participants completed the study, which included 51 (42.5\%) male and $69(57.5 \%)$ female patients. The mean age was $44.2 \pm 9.8$ years and mean body mass index (BMI) of $27.1 \pm 4.4 \mathrm{~kg} / \mathrm{m}^{2}$.

Three blood pressure dipping patterns were reported as no participant exhibited extreme BP dipping pattern. Dipping, non-dipping, and reverse dipping were reported in 21 (21.7\%), 61 $(50.8 \%)$, and $33(27.5 \%)$ participants respectively, as shown in figure 1 . The nondipping pattern was the most prevalent of the circadian rhythm abnormalities. Clinical characteristics of the three BP dipping patterns is shown table 2. Participants with the reverse BP dipping pattern were older than the dippers and the non-dippers $(48.8 \pm 8.6$ years vs $43.1 \pm 9.6$ vs $42.1 \pm 9.8$ years) respectively; $p$-value $=0.005$. The mean 24-hour SBP, daytime SBP, and night-time SBP and DBP differ significantly. Patients with the reverse BP dipping pattern had the lowest mitral E/A ratio compared with the normal dipping and non-dipping patterns $(1.0 \pm 0.3 \mathrm{vs}$ $1.3 \pm 0.5$ vs $1.1 \pm 0.3$ ) respectively; $p$-value $=0.006$. 
The characteristics of those with LVH and without LVH are shown in table 3. Office SBP is the only predictor of LVH in the study population (Odd ratio $=1.05,95 \%$ confidence interval $=1.00-1.10,0.034)$. Every unit increase in office SBP increased the chance of developing LVH by $5 \%$.

\section{DISCUSSION}

In this study, the non-dipping pattern was the most prevalent abnormality of diurnal BP variation in our patients with newly diagnosed hypertension, which is similar to previous studies $(11,19)$. We have shown that patients with the reverse dipping pattern had the lowest mitral E/A ratio, hence they were at greatest risk of diastolic dysfunction and hypertension-mediated organ damage. Additionally, this study showed office blood pressure was the only predictor of left ventricular hypertrophy. Other previous studies have also linked the non-dipping BP pattern with target organ damage and a higher risk of cardiac and extracardiac morbidity and mortality $(10,20)$; while associating this diurnal $\mathrm{BP}$ variation with factors such as advanced age, stress, poor social support, low socioeconomic status, sleep quality and quantity, apnoea, anger/temperament and personality types $(10,20)$.

Similar to previous studies, the reverse dippers were older and had higher mean 24-hour SBP, day-time SBP \& DBP, mean night-time SBP $\&$ DBP than the normal dippers and the nondippers respectively. These findings are in concordance with a previous study that showed that reduced dipping patterns were commoner in the older age groups than in the younger agegroups (21). An association between higher 24hour ABPM measurement and increased cardiovascular mortality, myocardial infarction and stroke has been documented (22). Some other researchers have also described a linear and inverse relationship between cardiovascular mortality and the nocturnal decline in BP with every $5 \%$ decline in nocturnal dip, being associated with $20 \%$ rise in the risk of cardiovascular death (22. Furthermore, reverse dipping pattern has been previously associated with obstructive sleep apnoea, which also portends an increased cardiovascular risk (23). In particular, reverse dippers with essential hypertension have been found to have more advanced hypertension-mediated organ damage (24-29). Therefore, patients with hypertension who have the reverse dipping pattern are at the highest risk of target organ damage and consequent complications. Furthermore, a higher night-time (nocturnal) BP measurement was reported to be significantly associated with greater risks of death and composite cardiovascular outcomes (non-fatal coronary event, heart failure and stroke) in a large population-based cohort study involving adults in Europe, Asia and South America (22). Underlying pathophysiologic mechanisms that have been suggested include factors such as abnormal neurohormonal regulation, lack of exercise, consumption of excess dietary sodium, and tobacco smoking have been implicated in the decline in nocturnal BP (30).

Finally, the study revealed that those with LVH had higher office SBP and DBP, 24hour SBP \& DBP, daytime SBP \& DBP, and only night-time DBP values. We however found office SBP to be the only independent predictor of left ventricular hypertrophy in our study population. However, a number of the studies have shown that ambulatory BP measurements were better predictors of hypertension-mediated organ damage than office BP $(6,7,31)$. Noteworthily, Odili et al. showed that office BP measurement may still have a significant role in risk stratification in resource-poor settings of sub-Saharan Africa (32).

\section{CONCLUSION}

This study revealed that the non-dipping pattern was the most prevalent abnormality of diurnal BP variation. Secondly, the reverse dippers had the lowest mitral E/A ratio putting them at the greatest risk of diastolic dysfunction. Lastly, office blood pressure was the only predictor of left ventricular hypertrophy. Hence, office BP measurement as well as ambulatory blood pressure measurements are important tools in risk stratification in resource-poor settings of sub-Saharan Africa.

Study Strengths: There is dearth of data on 24hour ABPM in hypertensive patients in Nigeria and sub-Saharan Africa. This study is one of the first studies in the country, on the association between blood pressure dipping patterns and hypertension-mediated organ damage among patients with hypertension. This study will add to the few published data in this field.

Also, the data used in the research was collected first-hand by the researchers having carefully and rigorously designed the method to ensure accuracy, quality, and integrity. The data for the main study was collected data from real sample populations. Furthermore, the researchers did not experience any event suggesting that the 
people may have given unacceptable or untruthful data because the readings were electronically measured from the BP machine.

Limitation of the study: The data are crosssectional, hence casual inference is weak. However, hypotheses generated from it can be further tested in other centres in the country.

Authors' contributions: DBF, OJA, OOD, KPM, KIA, OAB, AMA, AA were involved in the conception and design of the study data collection, collation, data analysis, data interpretation, and manuscript proofreading.

Conflict of interests: The authors declare no competing interests.

Funding details: The authors declare that the research was solely funded by them.

Disclosure statement: The authors declare no competing interests.

\section{REFERENCES}

1. Mills KT, Bundy JD, Kelly TN. Global Disparities of Hypertension Prevalence and Control: A Systematic Analysis of Population-Based Studies From 90 Countries. Circulation. 2016;134(6):441-450.

2. Yoon SS, Carroll MD, Fryar CD. Hypertension prevalence and control among adults: United States, 2011-2014. NCHS Data Brief. 2015; 220:1-8.

3. Albertus P, Morgenstern H, Robinson B, Saran R. Risk of ESRD in the United States. Am J Kidney Dis. 2016; 68:862-872

4. Gillum RF, Mehari A, Curry B, Obisesan TO. Racial and geographic variation in coronary heart disease mortality trends. BMC Public Health. 2012;12:410.

5. Gorostidi M, Banegas JR, de la Sierra A, Vinyoles E, Segura J, Ruilope LM. Ambulatory blood pressure monitoring in daily clinical practice - the Spanish ABPM Registry experience. Eur J Clin Invest. 2016;46(1):92-8.

6. Hermida RC, Ayala DE, Fernández JR, Mojón A, Smolensky MH. Hypertension: New perspective on its definition and clinical management by bedtime therapy substantially reduces cardiovascular disease risk. Eur J Clin Invest. 2018;48(5):e12909.

7. Yano Y, Hoshide S, Shimizu M, Eguchi K, Ishikawa J, Ishikawa S, et al. Association of home and ambulatory blood pressure changes with changes in cardiovascular biomarkers during antihypertensive treatment. Am J Hypertens. 2012;25(3):306-12.

8. Verdecchia P, Clement D, Fagard R, Palatini P,
Parati G. Blood Pressure Monitoring. Taskforce III: Target-organ damage, morbidity and mortality. Blood Press Monit. 1999;4(6):303-17.

9. Park JH, Lee HS, Kim JH, Lee JH, Kim J, Choi SW. Reverse dipper and high night-time heart rate in the acute stage of cerebral infarction are associated with increased mortality. J Stroke Cerebrovasc Dis. 2014;23(5):1171-6.

10. Taylor KS, Heneghan CJ, Stevens RJ, Adams EC, Nunan D, Ward A. Heterogeneity of prognostic studies of 24-hour blood pressure variability: systematic review and meta-analysis. PLoS One. 2015;10(5):e0126375.

11. Amjo IF AR, Akinyele OA, Olanipekun OA, Adesanya OS, Williams OT, et al. Diurnal rhythm of blood pressure among Nigerians with hypertension using 24-hour ambulatory blood pressure monitoring. PAMJ. 2020;36(240).

12. Adeoye AM, Adebiyi AO, Adebayo OM, Owolabi MO. Medication adherence and 24-h blood pressure in apparently uncontrolled hypertensive Nigerian patients. Niger Postgrad Med J. 2019;26(1):18-24.

13. Adeoye AM, Tayo BO, Owolabi MO, Adebiyi AA, Lackland DT, Cooper R, et al. Ambulatory blood pressure threshold for black Africans: more questions than answers. J Clin Hypertens (Greenwich). 2018;20(5):847-9.

14. Chobanian AV, Bakris GL, Black HR, Cushman WC, Green LA, Izzo JL, Jr., et al. The Seventh Report of the Joint National Committee on Prevention, Detection, Evaluation, and Treatment of High Blood Pressure: the JNC 7 report. JAMA. 2003;289(19):2560-72.

15. Parati G, Stergiou G, O'Brien E, Asmar R, Beilin L, Bilo G, et al. European Society of Hypertension practise guidelines for ambulatory blood pressure monitoring. J Hypertens. 2014;32(7):1359-66.

16. Lang RM, Badano LP, Mor-Avi V, Afilalo J, Armstrong A, Ernande L, et al. Recommendations for cardiac chamber quantification by echocardiography in adults: an update from the American Society of Echocardiography and the European Association of Cardiovascular Imaging. Eur Heart J Cardiovasc Imaging. 2015;16(3):233-70.

17. Jingi AM, Noubiap JJ, Kamdem P, Kingue S. Determinants and improvement of electrocardiographic diagnosis of left ventricular hypertrophy in a black African population. PLoS One. 2014;9(5):e96783.

18. Lang RM, Badano LP, Mor-Avi V, Afilalo J, Armstrong A, Ernande L, et al. Recommendations for cardiac chamber quantification by echocardiography in adults: an update from the American Society of Echocardiography and the European Association of Cardiovascular Imaging. J Am Soc Echocardiogr. 2015;28(1):139.e14.

19. Kawamura H, Ozawa Y, Izumi Y, Kasamaki Y, Nakayama T, Mitsubayashi H, et al. Non-dipping blood pressure variations in adult Kazakhs are 
derived from decreased daytime physical activity and increased nighttime sympathetic activity. Clin Exp Hypertens. 2016;38(2):194-202.

20. Palatini P, Reboldi G, Beilin LJ, Casiglia E, Eguchi K, Imai Y, et al. Added predictive value of night-time blood pressure variability for cardiovascular events and mortality: the Ambulatory Blood Pressure-International Study. Hypertension. 2014;64(3):487-93.

21. Mahdi A, Watkinson P, McManus RJ, Tarassenko L. Circadian blood pressure variations computed from 1.7 million measurements in an acute hospital setting. Am J Hypertens. 2019.

22. Yang WY, Melgarejo JD, Thijs L, Zhang ZY, Boggia J, Wei FF, et al. Association of Office and Ambulatory Blood Pressure With Mortality and Cardiovascular Outcomes. JAMA. 2019;322(5):409-20.

23. Genta-Pereira DC, Furlan SF, Omote DQ, Giorgi DMA, Bortolotto LA, Lorenzi-Filho G, et al. Nondipping Blood Pressure Patterns Predict Obstructive Sleep Apnea in Patients Undergoing Ambulatory Blood Pressure Monitoring. Hypertension. 2018;72(4):979-85.

24. Dolan E, Stanton A, Thijs L, Hinedi K, Atkins N, McClory S, et al. Superiority of ambulatory over clinic blood pressure measurement in predicting mortality: the Dublin outcome study. Hypertension. 2005;46(1):156-61.

25. Yano Y, Tanner RM, Sakhuja S, Jaeger BC, Booth JN, 3rd, Abdalla M, et al. Association of Daytime and Nighttime Blood Pressure With Cardiovascular Disease Events Among African American Individuals. JAMA Cardiol. 2019;4(9):910-7.

26. Abdalla M, Caughey MC, Tanner RM, Booth JN, 3rd, Diaz KM, Anstey DE, et al. Associations of
Blood Pressure Dipping Patterns With Left Ventricular Mass and Left Ventricular Hypertrophy in Blacks: The Jackson Heart Study. J Am Heart Assoc. 2017;6(4).

27. Eyuboglu M, Karabag Y, Karakoyun S, Akdeniz B. The effect of circadian blood pressure pattern on the presence of fragmented QRS complexes in hypertensive subjects. J Am Soc Hypertens. 2017;11(8):513-8.

28. Rodrigues JCL, Amadu AM, Ghosh Dastidar A, Harries I, Burchell AE, Ratcliffe LEK, et al. Noctural dipping status and left ventricular hypertrophy: A cardiac magnetic resonance imaging study. J Clin Hypertens (Greenwich). 2018;20(4):784-93.

29. Tadic M, Cuspidi C, Celic V, Pencic B, Mancia G, Grassi G, et al. The Prognostic Effect of Circadian Blood Pressure Pattern on Long-Term Cardiovascular Outcome is Independent of Left Ventricular Remodeling. J Clin Med. 2019;8(12).

30. Kanbay M, Turgut F, Uyar ME, Akcay A, Covic A. Causes and mechanisms of non-dipping hypertension. Clin Exp Hypertens. 2008;30(7):585-97.

31. Aparicio LS, Barochiner J, Peuchot VA, Giunta DH, Martínez R, Morales MS, et al. Comparing Office, Central, Home and Ambulatory Blood Pressure in Predicting Left Ventricular Mass. Hipertens Riesgo Vasc. 2019;36(1):5-13.

32. Odili AN, Thijs L, Yang WY, Ogedengbe JO, Nwegbu MM, Jacobs L, et al. Office and Home Blood Pressures as Determinants of Electrocardiographic Left Ventricular Hypertrophy Among Black Nigerians Compared With White Flemish. Am J Hypertens. 2017;30(11):1083-92

How to cite this article:

Dele-Ojo, B.F., Ogunmodede J.A., Ojo O.D., Kolo P.M., Katibi I.A., Omotoso A.B., Adeoye M.A., Adesokan A. Association between blood pressure dipping patterns and hypertension-mediated organ damage among Nigerians with newly-diagnosed hypertension. Research Journal of Health Sciences, 2021, 9(3): 197-206 
Table 1: General Characteristics of the Study Population

\begin{tabular}{ll}
\hline Variable & $\begin{array}{l}\text { N=120 } \\
\text { Mean } \pm \text { SD }\end{array}$ \\
\hline Gender & $51(42.5 \%)$ \\
$\quad$ Male, $\mathrm{n}(\%)$ & $69(57.5 \%)$ \\
Female, $\mathrm{n}(\%)$ & $44.2 \pm 9.8$ \\
Age (years) & $27.1 \pm 4.4$ \\
Body Mass Index $\left(\mathrm{Kg} / \mathrm{m}^{2}\right)$ & $90.1 \pm 13.1$ \\
Waist Circumference $(\mathrm{cm})$ & $0.9 \pm 0.1$ \\
Waist-hip Ratio & $152.9 \pm 17.2$ \\
Systolic Blood Pressure (mmHg) & $95.8 \pm 12.4$ \\
Diastolic Blood Pressure (mmHg) & $136.8 \pm 14.3$ \\
Average Total Systolic BP (mmHg) & $83.7 \pm 11.4$ \\
Average Total Diastolic BP (mmHg) & $137.9 \pm 14.2$ \\
Daytime Systolic Blood Pressure (mmHg) & $85.1 \pm 11.6$ \\
Daytime Diastolic Blood Pressure (mmHg) & $132.1 \pm 17.2$ \\
Night-time Systolic Blood Pressure (mmHg) & $78.7 \pm 11.6$ \\
Night-time Diastolic Blood Pressure (mmHg) & $3.5 \pm 0.5$ \\
Left atrial diameter (cm) & $4.6 \pm 0.5$ \\
Left ventricular end-diastolic diameter $(\mathrm{cm})$ & $3.0 \pm 0.5$ \\
Left ventricular end-systolic diameter $(\mathrm{cm})$ & $139.7 \pm 36.4$ \\
Left ventricular mass (g) & $0.5 \pm 0.0$ \\
Relative wall thickness & $64.8 \pm 7.9$ \\
Ejection fraction (\%) & $35.8 \pm 6.2$ \\
Fractional shortening (\%) & $1.1 \pm 0.3$ \\
Mitral E/A ratio & $179.1 \pm 74.9$ \\
Deceleration time (ms) & $107.8 \pm 16.8$ \\
Isovolumetric time(ms) & \\
\hline
\end{tabular}

Key: SD, standard deviation

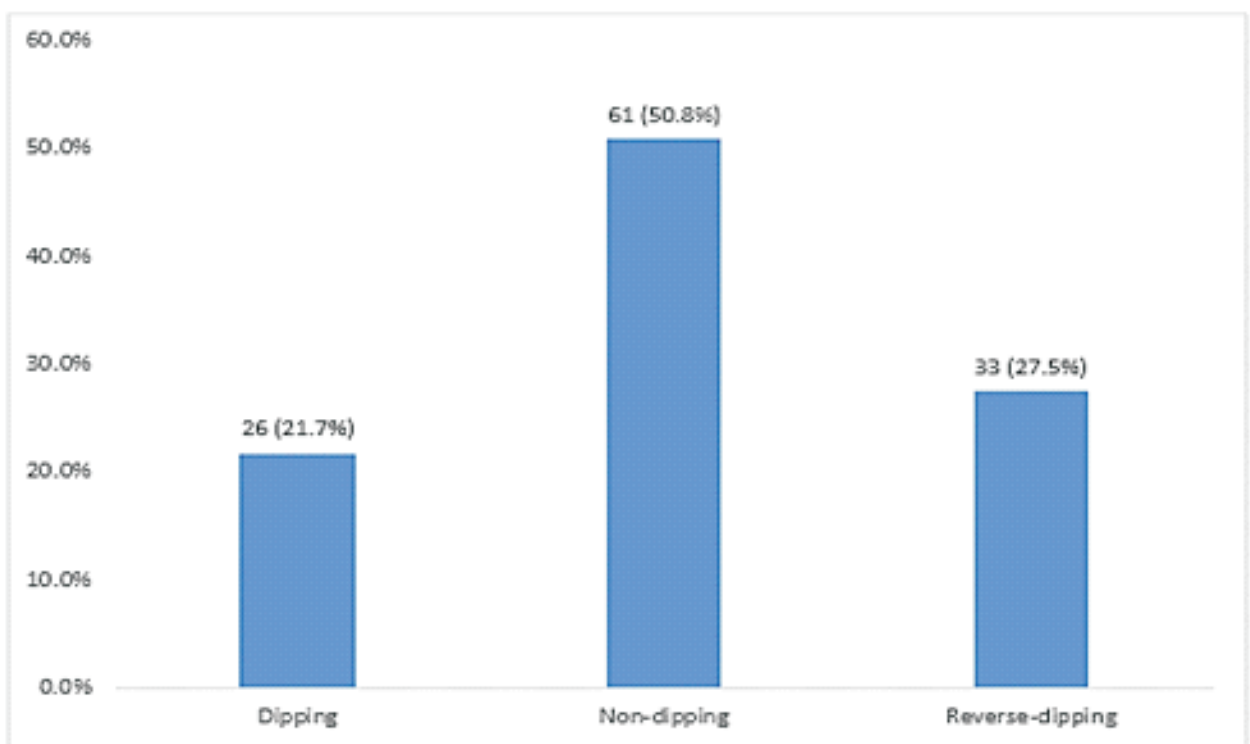

Figure 1: Prevalence of blood pressure dipping patterns in the study population 
Table 2: Characteristics Stratified by Blood Pressure Dipping Patterns

\begin{tabular}{|c|c|c|c|c|}
\hline Variable &  & $\begin{array}{l}\text { Non-Dippers } \\
(\mathbf{n}=\mathbf{6 1}) \\
\text { Mean } \pm \text { SD } \\
\end{array}$ & $\begin{array}{l}\text { Reverse } \\
\text { Dippers }(\mathbf{n}=\mathbf{3 3}) \\
\text { Mean } \pm \text { SD } \\
\end{array}$ & p-value \\
\hline Gender & & & & 0.201 \\
\hline Male, n (\%) & $15(29.4)$ & $24(47.1)$ & $12(23.5)$ & \\
\hline Female, n (\%) & $11(15.9)$ & $37(53.6)$ & $21(30.4)$ & \\
\hline LVH & & & & 0.692 \\
\hline Yes, n (\%) & $22(84.6)$ & $48(78.7)$ & $28(84.8)$ & \\
\hline No, n $(\%)$ & $4(15.4)$ & $13(21.3)$ & $5(15.2)$ & \\
\hline Age (years) & $43.1 \pm 9.6$ & $42.1 \pm 9.8$ & $48.8 \pm 8.6$ & $0.005^{* \alpha}$ \\
\hline Body Mass Index $\left(\mathrm{Kg} / \mathrm{m}^{2}\right)$ & $27.0 \pm 3.9$ & $27.1 \pm 3.8$ & $27.2 \pm 5.6$ & 0.982 \\
\hline Waist Circumference (cm) & $86.3 \pm 12.2$ & $90.5 \pm 13.5$ & $92.4 \pm 12.8$ & 0.195 \\
\hline Waist-hip Ratio & $0.9 \pm 0.0$ & $0.9 \pm 0.1$ & $0.9 \pm 0.1$ & 0.229 \\
\hline Systolic Blood Pressure (mmHg) & $152 \pm 17.2$ & $150 \pm 14.3$ & $159 \pm 20.8$ & 0.051 \\
\hline Diastolic Blood Pressure (mmHg) & $97.0 \pm 13.0$ & $96.4 \pm 12.0$ & $93.8 \pm 12.7$ & 0.546 \\
\hline 24-hour Systolic BP (mmHg) & $138.3 \pm 18.2$ & $133.1 \pm 11.4$ & $142.4 \pm 14.0$ & $0.008 * \pi$ \\
\hline 24-hour Diastolic BP (mmHg) & $84.4 \pm 12.7$ & $82.5 \pm 11.1$ & $85.3 \pm 11.1$ & 0.496 \\
\hline Daytime Systolic Blood Pressure (mmHg) & $142 \pm 18.5$ & $134.7 \pm 11.8$ & $140.7 \pm 13.3$ & $0.038 * 8$ \\
\hline Daytime Diastolic Blood Pressure (mmHg) & $87.4 \pm 13.1$ & $84.1 \pm 11.1$ & $85.3 \pm 11.5$ & 0.493 \\
\hline Night-time Systolic Blood Pressure ( $\mathrm{mmHg}$ ) & $123.3 \pm 16.0$ & $126.8 \pm 10.2$ & $148.8 \pm 17.2$ & $<0.001^{* \mu}$ \\
\hline Night-time Diastolic Blood Pressure (mmHg) & $72.0 \pm 9.8$ & $78.0 \pm 10.8$ & $85.1 \pm 11.1$ & $<0.001 * \beta$ \\
\hline Left atrial diameter $(\mathrm{cm})$ & $3.4 \pm 0.7$ & $3.6 \pm 0.5$ & $3.5 \pm 0.5$ & 0.532 \\
\hline $\operatorname{LVEDD}(\mathrm{cm})$ & $4.6 \pm 0.5$ & $4.6 \pm 0.5$ & $4.7 \pm 0.6$ & 0.680 \\
\hline $\operatorname{LVESD}(\mathrm{cm})$ & $2.9 \pm 0.4$ & $3.0 \pm 0.5$ & $3.0 \pm 0.5$ & 0.650 \\
\hline $\operatorname{LVM}(g)$ & $254.6 \pm 57.8$ & $248.4 \pm 62.5$ & $270.5 \pm 95.8$ & 0.368 \\
\hline $\operatorname{LVMI}\left(\mathrm{g} / \mathrm{m}^{2}\right)$ & $138.1 \pm 32.1$ & $134.3 \pm 31.4$ & $150.9 \pm 45.6$ & 0.105 \\
\hline Relative wall thickness & $0.4 \pm 0.0$ & $0.5 \pm 0.0$ & $0.5 \pm 0.0$ & 0.749 \\
\hline Ejection fraction (\%) & $67.3 \pm 7.7$ & $63.9 \pm 8.0$ & $64.6 \pm 7.8$ & 0.180 \\
\hline Fractional shortening (\%) & $37.7 \pm 6.3$ & $35.1 \pm 6.1$ & $35.6 \pm 6.0$ & 0.192 \\
\hline Mitral E/A ratio & $1.3 \pm 0.5$ & $1.1 \pm 0.3$ & $1.0 \pm 0.3$ & $0.006^{* 8}$ \\
\hline DT (ms) & $186.2 \pm 76.9$ & $178.8 \pm 69.1$ & $174.1 \pm 85.1$ & 0.829 \\
\hline IVRT (ms) & $107.8 \pm 16.9$ & $105.6 \pm 17.9$ & $111.8 \pm 14.4$ & 0.237 \\
\hline
\end{tabular}

Keys: ", statistically significant; LA, left atrium; LVIDD, left ventricular internal dimension in diastole; $L V I S D$, left ventricular internal dimension in systole; FS, fractional shortening; EF, ejection fraction; $L V M$, left ventricular mass; LVMI, left ventricular mass index; RWT, relative wall thickness; $D T$ - deceleration time; IVRT, isovolumetric relaxation time.

Where the significance lies: $\alpha$-reverse dippers significantly greater than normal dippers, $\pi$-reverse dippers significantly greater than non-dippers, 8 - normal dippers significantly greater than non-dippers, $\mu$-reverse dippers significantly greater than normal dipping patterns.

$\beta$-reverse dipping pattern is greater than the non-dipping pattern, the non-dipping pattern is greater than the dipping pattern. 
Table 3: Characteristics stratified by the presence of Left Ventricular Hypertrophy

\begin{tabular}{llll}
\hline \multirow{2}{*}{ Variables } & $\begin{array}{l}\text { LVH } \\
(\mathbf{n = 9 8}) \\
\text { Mean } \pm \text { SD }\end{array}$ & $\begin{array}{l}\text { NO LVH } \\
(\mathbf{n = 2 2}) \\
\text { Mean } \pm \text { SD }\end{array}$ & p-value \\
\hline Age & $43.9 \pm 9.8$ & $45.5 \pm 10.2$ & 0.495 \\
Body mass index & $27.5 \pm 4.4$ & $25.6 \pm 4.0$ & 0.066 \\
Waist circumference & $91.0 \pm 13.4$ & $86.1 \pm 11.3$ & 0.111 \\
Waist-hip ratio & $0.9 \pm 0.1$ & $0.9 \pm 0.1$ & 0.673 \\
Office Systolic Blood Pressure & $154.9 \pm 17.4$ & $144.2 \pm 13.3$ & $0.008^{*}$ \\
Office Diastolic Blood Pressure & $97.1 \pm 12.1$ & $90.1 \pm 12.3$ & $0.016^{*}$ \\
Ambulatory 24-hour SBP (mmHg) & $138.2 \pm 14.6$ & $130.4 \pm 10.9$ & $0.020^{*}$ \\
Ambulatory 24-hour DBP (mmHg) & $84.8 \pm 11.7$ & $78.4 \pm 8.4$ & $0.015^{*}$ \\
Ambulatory daytime SBP (mmHg) & $139.4 \pm 14.5$ & $131.6 \pm 10.6$ & $0.019^{*}$ \\
Ambulatory daytime DBP (mmHg) & $86.4 \pm 11.9$ & $79.5 \pm 8.6$ & $0.011^{*}$ \\
Ambulatory night-time SBP (mmHg) & $133.5 \pm 17.6$ & $126.0 \pm 13.7$ & 0.065 \\
Ambulatory night-time DBP (mmHg) & $79.7 \pm 11.9$ & $74.0 \pm 8.8$ & $0.034^{*}$ \\
\hline
\end{tabular}

Keys: SBP, systolic blood pressure; DBP, diastolic blood pressure;

$L V H$, left ventricular hypertrophy, ${ }^{*}$, statistically significant.

Table 4: Predictor of left Ventricular hypertrophy in the Study Population

\begin{tabular}{|c|c|c|c|}
\hline Variables & Odd Ratio & $\begin{array}{l}\text { 95\% Confidence } \\
\text { Interval }\end{array}$ & p-value \\
\hline Age (years) & 0.946 & $0.893-1.003$ & 0.063 \\
\hline Waist circumference $(\mathrm{cm})$ & 1.035 & $0.994-1.078$ & 0.093 \\
\hline Office SBP (mmHg) & 1.050 & $1.004-1.098$ & $0.034 *$ \\
\hline Office DBP (mmHg) & 1.006 & $0.950-1.065$ & 0.838 \\
\hline $\begin{array}{l}\text { Ambulatory day-time SBP } \\
(\mathrm{mmHg})\end{array}$ & 0.973 & $0.882-1.075$ & 0.593 \\
\hline $\begin{array}{l}\text { Ambulatory day-time DBP } \\
(\mathrm{mmHg})\end{array}$ & 1.068 & $0.961-1.188$ & 0.224 \\
\hline $\begin{array}{l}\text { Ambulatory night-time SBP } \\
(\mathrm{mmHg})\end{array}$ & 1.008 & $0.943-1.077$ & 0.817 \\
\hline $\begin{array}{l}\text { Ambulatory night-time DBP } \\
(\mathrm{mmHg})\end{array}$ & 0.994 & $0.908-1.088$ & 0.889 \\
\hline
\end{tabular}

